\title{
Vitamin D and extraskeletal effects
}

\author{
Vitamina $D$ şi efectele extrascheletice \\ Andra BURUIANĂ ${ }^{1,2}$, Eugenia NEDELTCHEVA-PETROVA ${ }^{1,2}$, Nicoleta DUMITRU $^{1}$, Maria OLARU ${ }^{1}$, \\ Ion COCOLOŞ3 ${ }^{3}$ Mara CARŞOTE ${ }^{1,2}$, Adina GHEMIGIAN ${ }^{1,2}$ \\ ${ }^{1}$ Institutul Național de Endocrinologie "C.I. Parhon", Bucureşti, România \\ 2Universitatea de Medicină şi Farmacie „Carol Davila“, Bucureşti, România \\ ${ }^{3}$ Spitalul Clinic de Urgență, Bucureşti, România
}

\begin{abstract}
Vitamin $D$ is a fat soluble vitamin and a steroid hormone with endocrine, paracrine and autocrine actions. The two major forms are vitamin D2 (ergocalcifeol) and vitamin D3 (cholecalciferol), the active hormone being calcitriol. The importance of vitamin $D$ and its metabolites lies in the key role in calcium homeostasis and bone metabolism but vitamin $D$ also has extraskeletal effects, still incompletely understood. Vitamin D receptor (VDR) is ubiquitous in the body, the presence of VDR in multiple tissues suggesting a more general role of calcitriol. Vitamin D can regulate many cellular functions such as cell proliferation, differentiation, and apoptosis. Calcitriol exerts immunomodulating and antiproliferative effects and plays a potential role in the prevention and therapy of various cancers (breast, colorectal, prostate, thyroid), autoimmune diseases (rheumatoid arthritis, systemic lupus ery thematosus, inflammatory bowel disease, multiple sclerosis and type 1 diabetes, thyroid autoimmunity), obesity and also in cardiovascular, renal, maternal-fetal pathologies.

Conclusions. The current studies bring increasingly more evidence about the benefits of vitamin D supplementation in extraskeletal pathology although there is no agreed protocol in this regard. However, these patients should be considered for adequate intake of vitamin $D$ for the prevention, improving the evolution and the prognosis of their disease.
\end{abstract}

Keywords: vitamin D, VDR, cancer, autoimmunity

\section{REZUMAT}

Vitamina D este o vitamină liposolubilă şi un hormon steroidian cu acțiune endocrină, paracrină şi autocrină. Cele două forme majore sunt vitamina D2 (ergocalcifeol) şi vitamina D3 (colecalciferol), hormonul activ fiind calcitriolul. Importanța vitaminei $D$ şi a metaboliților săi rezidă din rolul cheie în homeostazia calciului şi a metabolismului osos, însă vitamina $D$ are şi efecte extrascheletice, încă incomplet elucidate. Receptorul vitaminei $D(V D R)$ este ubicuitar în organism, prezența VDR în aceste țesuturi sugerând un rol mai general al calcitriolului. Vitamina D poate regla multe funcții celulare cum ar fi proliferarea, diferențierea celulară şi apoptoza. Calcitriolul exercită efecte imunomodulatoare şi anti-proliferative, jucând un rol potențial în acțiunea preventivă sau terapeutică în diferite tipuri de cancer (mamar, colorectal, prostatic, tiroidian), boli autoimune (artrita reumatoidă, lupusul eritematos sistemic, bolile inflamatorii intestinale, scleroza multiplă şi diabetul zaharat de tip 1, autoimunitatea tiroidiană), in obezitate precum şi afecțiuni cardiovasculare, renale, materno-fetale.

Concluzii. Studiile actuale aduc din ce în ce mai multe dovezi cu privire la beneficiile suplimentării cu vitamina $D$ in patologia extrascheletică deşi nu există un protocol recunoscut în acest sens. Totuşi, la aceşti pacienți trebuie avut în vedere aportul adecvat de vitamina $D \mathrm{cu}$ scopul prevenirii, ameliorării evoluției şi prognosticului bolii de fond.

Cuvinte cheie: vitamina D, VDR, cancer, autoimunitate 


\author{
Abrevieri \\ 7-DHC = 7-dehidrocolesterol \\ 25(OH)D = 25 hidroxi vitamina $D$ \\ $1,25(\mathrm{OH})_{2} \mathrm{D}=1,25$ dihidroxi vitamina $\mathrm{D}$ \\ BGB = boală Graves Basedow \\ DZ1 = diabet zaharat tip 1
}

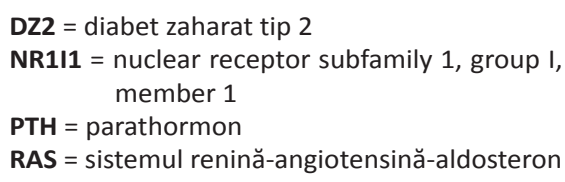

UV = ultraviolete

UVB = ultraviolete tip B

VDR = receptorul vitaminei $D$

VDRE $=$ vitamin $\mathrm{D}$ response element
Vitamina D este o vitamină liposolubilă și un hormon steroidian cu acțiune endocrină, paracrină și autocrină. Vitamina D3 (colecalciferol) este produsă din 7-dehidrocolesterol (7-DHC) printr-un proces în două etape în care inelul $B$ este desfăcut de razele UV (spectru 280-320 UVB), formând pre-vitamina D3 care izomerizează în vitamina D3. Atât intensitatea UVB, cât și pigmentarea pielii contribuie la rata de formare a D3. Vitamina D2 (ergocalciferol) este produsă prin iradierea UVB a ergosterolului din plante și fungi (de exemplu, ciuperci) (1-5). Pentru a deveni activă, vitamina D3 suferă 2 hidroxilări: 25hidroxilarea la nivelul ficatului, rezultând astfel 25-hidroxi vitamina D [25(OH)D] care este forma circulantă principală, respectiv $1 \alpha$ hidroxilarea renală în urma căreia se formează metabolitul activ 1,25-dihidroxi-vitamina $\mathrm{D}\left[1,25(\mathrm{OH})_{2} \mathrm{D}\right](6-8)$. Rolul clasic al calcitriolului în metabolismul fosfocalcic constă în stimularea absorbției intestinale de calciu și fosfor, a reabsorbției renale de calciu și în reglarea secreției de parathormon (PTH). Acțiunile vitaminei $D$ sunt realizate prin legarea de receptorul specific (VDR) situat la nivelul nucleului în celulele țintă. Receptorul vitaminei D este larg distribuit în multe țesuturi, această distribuție extinsă stând la baza multitudinii acțiunilor extrascheletice (9).

Receptorul vitaminei $D$ este cunoscut și sub denumirea de NR1I1 (nuclear receptor subfamily 1 , group I, member 1). Gena VDR, localizată pe cromozomul 12q12-q14, are cel puțin 5 regiuni promotor, aparține superfamiliei de receptori nucleari și modulează transcripția genelor țintă ca răspuns la 1,25(OH)2 D3, hormon imunomodulator. Vitamina $D$ formează homodimeri sau heterodimeri cu receptorul hormonilor tiroidieni, dar mai ales cu receptorii retinoizi X (RXR$\alpha, \beta, \gamma)$. Aceste complexe se leagă de elementele de răspuns (vitamin $D$ response element-VDRE) interacționând cu coactivatori și corepresori ai genei țintă (4). Mai multe variante alelice (polimorfisme) au fost descrise la nivelul genei VDR și au fost raportate ca fiind asociate cu o varietate de fenotipuri fiziologice și patologice (rahitism, rezistență la vitamina $D$, hiperparatiroidism, susceptibilitatea la infecții, boli autoimune și cancer). Există patru polimorfisme de nucleotide în gena VDR, care au fost cel mai des investigate: Fokl (în exonul 2), Bsml și Apal (în intronul 8) și Taql (în exonul 9) $(10,11)$.

Principalele patologii extrascheletice în care a fost incriminat deficitul de vitamina D:

\section{Vitamina $D$ și autoimunitatea}

Pe lângă rolurile bine cunoscute, vitamina $D$ este considerată un imunomodulator important care poate afecta fiziopatologia unor boli autoimune precum lupusul eritematos sistemic, diabetul zaharat tip 1, artrita reumatoidă, bolile inflamatorii intestinale, scleroza multiplă, bolile autoimune tiroidiene $(12,13)$. Aportul suplimentar de vitamina $D$ este considerat a influența favorabil debutul și/sau evoluția acestora (13).

Vitamina $D$ exercită multiple efecte asupra celulelor sistemului imun, ea modulând răspunsurile imune înnăscute și adaptative. Vitamina D activă stimulează imunitatea înnăscută, intensificând expresia VDR și a 1ahidroxilazei atunci când un monocit/macrofag este stimulat de un agent infecțios. $1,25(\mathrm{OH})_{2} \mathrm{D}$ pătrunde în nucleu și crește expresia cathelicidinei, peptid implicat în imunitate și care induce distrucția agentului patogen. $1,25(\mathrm{OH})_{2} \mathrm{D}$ supresează proliferarea celulelor $\mathrm{T}$, determinând schimbarea fenotipului Th1 în Th2 și facilitează inducerea celulelor T reglatoare. Aceste efecte determină scăderea producției de citokine proinflamatoare (IL-2, TNF $\alpha$ ) cu creșterea secreției de citokine antiinflamatoare (IL-4, IL-5, IL-10). De asemenea, inhibă diferențierea celulelor dendritice și o stimulează pe cea a macrofagelor $(14,15)$.

În ceea ce privește relația nivelului de vitamina $D$ cu bolile autoimune tiroidiene, expresia VDR și a $1 \alpha$-hidroxilazei a fost identificată în celulele foliculare tiroidiene. La pacienții cu Hashimoto a fost descrisă o corelație inversă între nivelul seric al 25HOvitaminei D și nivelul ATPO și ATG. În aceeași măsură, deficitul de vitamina D a fost invers corelat cu titrul TRab la pacienții cu boală Graves Basedow (BGB), rezultând astfel că tratamentul specific alături de corectarea carenței de vitamina $D$, poate determina inducerea mai precoce a statusului eutiroidian, precum și menținerea lui o perioadă mai îndelungată. Recent, studiile au demonstrat asocierea polimorfismelor genei receptorului vitaminei $\mathrm{D} \mathrm{cu}$ 
boala Graves-Basedow și tiroidita Hashimoto, existând însă o mare variabilitate genetică între populații (12,16-19).

\section{Vitamina D și statusul neuropsihic}

Vitamina D este incriminată în procese importante din timpul dezvoltării creierului, precum diferențierea și apoptoza celulară. A fost demonstrată asocierea deficitului de vitamina D cu riscul bolilor neurologice precum scleroza multiplă, boala Alzheimer, boala Parkinson, depresia, schizofrenia. Vitamina D interrelaționează cu factori imunoreglatori, antioxidanți, antiischemici, neurotrofici, dar și asupra neurotransmițătorilor (acetilcolina) și stimulează clearence-ul ßamiloidului de către macrofage $(20,21)$.

\section{Vitamina D și sistemul cardiovascular}

Studiile descriu o asociere între nivelul scăzut de vitamina D și riscul de hipertensiune arterială sau evenimente cardiovasculare (4). Mecanismele intricate considerate a fi responsabile de această corelație vizează în principal sistemul renină-angiotensină-aldosteron (RAS), dar și rezistența la insulină, obezitatea, diabetul zaharat și hiperparatiroidismul secundar. Vitamina D determină scăderea markerilor de inflamație (proteina C reactivă și IL-10) și a nivelului seric al markerilor de stres oxidativ: radicali liberi, oxid nitric. A fost demonstrat rolul calcitriolului în inhibiția transcripției genei reninei cu reducerea sintezei de renină și supresia consecutivă a RAS, aspect confirmat prin nivelul seric mai crescut la indivizii cu HTA esențială, precum și rolul în proliferarea cardiomiocitelor și a celulelor musculaturii vasculare. Un alt mecanism incrimat în protecția cardiovasculară constă în prevenirea leziunilor inflamatorii și oxidative la nivelul endoteliului vascular, precum și a procesului de ateroscleroză. Calcitriolul participă la ameliorarea profilului cardiovascular și prin efectele antidiabetice cu reducerea insulinorezistenței (22-26).

4. Vitamina $D$, diabetul zaharat și obezitatea

Vitamina D a fost corelată cu diabetul zaharat, obezitatea, sindromul metabolic și sensibilitatea la insulină prin rolul său imunomodulator și asupra celulelor $\beta$ pancreatice (4).

În diabetul zaharat de tip 2 (DZ2), patologie care asociază un risc cardiovascular, constituind o comorbiditate importantă, există un nivel crescut de citokine proinflamatorii (TNF $\alpha$, PCR, IL-6) asupra cărora își exercită efectul antiinflamator al 1,25(OH) 2 D. Vitamina D îmbunătățește activitatea beta-celulară și ameliorează sensibilitatea la insulină, modulând în același timp sinteza și secreția insulinei prin efecte genomice $(4,25,26)$.
În ceea ce privește diabetul zaharat de tip 1 (DZ1) care are ca mecanism fiziopatologic principal distrucția autoimună a celulelor $\beta$ pancreatice, corelația cu vitamina $D$ se bazează pe acțiunile imunomodulatoare și antiinflamatoare ale acesteia, care pot diminua insulinita autoimună caracteristică. Vitamina $D$ reduce distrucția celulelor $\beta$ pancreatice prin supresarea capacității de prezentare antigenică a macrofagelor, inhibarea maturării celulelor dendritice și, nu în ultimul rând, inhibarea producției de IFNץ și IL-2 (citokine ce activează macrofagele și limfocitele T citotoxice determinând distrucția celulară din DZ1) $(4,25,26)$.

Un alt aspect dovedit este nivelul mai scăzut de vitamina D la persoanele obeze comparativ cu cele normoponderale, VDR fiind exprimat și la nivelul adipocitelor, astfel încât IMC crescut este invers corelat cu concentrația 25(OH)D. Cauzele posibile pot fi aportul mai scăzut, expunerea mai redusă la soare față de persoanele normoponderale (de ex., din motive estetice), dar și faptul că vitamina D este liposolubilă, ea fiind sechestrată la nivelul țesutului adipos, necesitând doze mai mari de suplimentare $(4,25,26)$.

\section{Vitamina D și cancerul}

Există argumente semnificative privind implicarea vitaminei D în prevenția cancerului, VDR fiind exprimat în majoritatea țesuturilor. Rolul vitaminei D a fost studiat pentru: cancerul de sân, colorectal, prostatic, cutanat, ovarian, tiroidian, fără a avea însă rezultate concludente asupra unei doze optime necesare (4).

Studiile in vivo și in vitro sugerează că 1,25(OH)2 D promovează diferențierea celulară, inhibă proliferarea celulelor canceroase și are efecte antiinflamatoare, proaptotice și antiangiogenetice. Prin legarea la VDR, 1,25(OH)2 D stimulează apoptoza celulelor maligne prin reprimarea proteinelor de supraviețuire (BCL2, reverstranscriptaza, telomeraza), activarea proteinelor proapoptotice și antiangiogenice și crește sensibilitatea la radioterapie și chimioterapie (4, 25-27). Calcitriolul inhibă proliferarea celulelor maligne blocând ciclul celular, inhibând factori de creștere (IGF-1, TGFß) și cascadele Wnt/ßcatenin, MAPK 5, factorul nuclear KB(NFKB). Supresează invazia tumorală și metastazarea prin scăderea expresiei și activității serin proteazelor și metaloproteinazelor asociate invaziei celulare. Are și acțiuni la nivelul receptorilor, astfel încât inhibă transcripția receptorului de estrogen $\alpha$ la nivelul țesutului mamar și upreglează receptorul androgenic (AR) la nivelul prostatei (25-27). 
Pe lângă nivelul circulant scăzut al 1,25(OH) 2 regăsit la pacienții cu cancer, există și asocieri ale polimorfismelor VDR cu riscul și prognosticul în cancerul de sân (Bsml, Fokl, Taql), de prostată (Fokl), melanomul malign (Fokl, Bsml), carcinomul renal (Taql), colorectal (Fokl, Bsml, Taql) și carcinomul tiroidian diferențiat (Apal) (28-30).

\section{Vitamina $D$ și sistemul muscular}

Acțiunile vitaminei $D$ în țesutul muscular includ efecte genomice și non genomice prin intermediul receptorului VDR de la nivelul mușchiului. Nivelul seric al vitaminei $D$ este corelat pozitiv cu apariția sarcopeniei, performanța fizică și invers corelat cu riscul căderii (4,31-33).

Din punct de vedere clinic, caracteristică deficitului de vitamina $D$ este miopatia cu slăbiciunea musculaturii proximale cu atrofie progresivă (în special a fibrelor de tip II) și afectarea mersului („mers de pinguin“). Efectele vitaminei $D$ asupra musculaturii pot fi directe, prin legarea VDR de celula țintă sau indirecte, prin reglarea metabolimului fosfocalcic. Are efect inhibitor asupra expresiei genei miostatinului (hormon cu efect negativ asupra masei musculare) (3134). Deficitul de vitamina D determină apariția hiperparatiroidismului secundar, care influențează la rândul său funcția musculară. Vitamina D controlează influxul de calciu în celula musculară din compartimentul extracelular și mobilizarea $\mathrm{Ca}^{2+}$ din reticulul sarcoplasmatic în citosol și reglează captarea fosfatului inorganic la nivelul mușchilor pentru producția de energie necesară contracției. Un alt mecanism incriminat este reducerea insulinorezistenței la nivel muscular (31-36).

\section{CONCLUZII}

În concluzie, pe lângă patologia sistemului osos, deficitul de vitamina $D$ este din ce în ce mai des incriminat în etiopatogenia și evoluția unor boli extrascheletale sugerând astfel necesitatea existenței unui consens cu privire la suplimentarea de vitamina $D$ și dozele optime necesare prevenției și chiar tratamentului acestor boli.

Conflict of interest: none declared Financial support: none declared

\section{BIBLIOGRAFIE}

1. Shuler F.D., Lycans D., Salloum E. Extraskeletal effects of vitamin $D$ potential impact on WV disease morbidity and mortality; W V Med J. 2012 MayJun;108(3):56-62.

2. Institute of Medicine (US) Committee to Review Dietary Reference Intakes for Vitamin $\mathrm{D}$ and Calcium; Ross AC, Taylor CL, Yaktine AL, et al., editors. Washington (DC): National Academies Press (US); 2011;

3. Sassan Pazirandeh, David L. Burns. Overview of vitamin D. http://www.uptodate. com/contents/overview-of-vitamin-d;

4. Rosen C.J., Adams J.S., Bikle D., Black D. et al. The nonskeletal effects of vitamin D: An Endocrine Society Scientific Statement. Endocrine Reviews, june 2012, 33(3):456-492;

5. Holick M.F. Vitamin D: A millenium perspective. J Cell Biochem 2003; 88:296.

6. DeLuca H.F. Overview of general physiologic features and functions of vitamin D. Am J Clin Nutr 2004; 80:1689S.

7. Holick M.F., MacLaughlin J.A., Doppelt S.H. Regulation of cutaneous previtamin D3 photosynthesis in man: skin pigment is not an essential regulator. Science 1981; 211:590.

8. Christakos S., Ajibade D.V., Dhawan P. et al. Vitamin D: metabolism. Endocrinol Metab Clin North Am 2010; 39:243.
9. Dumitru N., Buruiana A., Petrova E. et al. Vitamina D si implicatiile materno-fetale. Practica medicala, vol 11, 2(45), 2016; 151-154;

10. Haiyang Zhou, Chenggang $X u$ and Mingjun Gu. Vitamin D receptor (VDR) gene polymorphisms and Graves' disease: a meta-analysis. Clinical Endocrinology (2009), 70, 938-945;

11. Buzinski S. Noi repere in studiul efectelor biologice ale vitaminei $\mathrm{D}$. Revista romana de pediatrie, 2011, vol LX(4): 310-322;

12. Ahuzaim O.N., Aljohani N. Effect of vitamin D3 on untreated Graves disease with vitamin D deficiency; Clinical Medicine Insights: Case reports 2014:7, 83-85;

13. Yasuda T., Okamoto Y., Hamada N. et al. Serum vitamin $D$ levels are decreased and associated with thyroid volume in female patients with newly onset Graves' disease. Endocrine (2012) 42: 739-741;

14. Aranow $C$. Vitamin $D$ and the immune system; J Investig Med. 2011, august; 59(6):881-886;

15. Cojocaru M., Cojocaru I.M. association between vitamin $D$ deficiency and autoimmune diseases; Revista Medicala Romana, vol LXI (1), 2014: 17-21;

16. Zhamg H., Liang L., Xie Z. Low vitamin D status is associated with increased thyrotropin-receptor antibody titer in Graves disease; Endocr Pract, 2015; 21(3): 258-263:

17. Bozkurt N.C., Karbek B., Ucan B. et al. The association between severity of vitamin $D$ deficiency and Hashimoto's thyroiditis. Endocr Pract. 2013; 19(3);

18. Shin D.Y., Kim K.J., Kim D., Hwan S., Lee E.J. Low vitamin $D$ is associated with anti-thyroid peroxidase antibody in autoimmune thyroiditis. Yonsei Med $\mathrm{J}$ 55(2):476-481, 2014;

19. Goswami R., Marwaha R.K., Gupta N. et al. Prevalence of vitamin $\mathrm{D}$ deficiency and its relationshup with thyroid autoimmunity in Asian indians: a community based survey; British J of Nutrition (2009), 102: 382-386;

20. Eyles D.W., Burne T.H.J., McGrath J.J. Vitamin $\mathrm{D}$, effects on brain development, adult brain function and the links between low levels of vitamin $D$ and neuropsychiatric disease. Front. Neuroendocrinol. Front Neuroendocrinol. 2013 Jan;34(1): 47-64;

21. Mpandzou G., Haddou A.B., Regragui W. et al. Vitamin $D$ deficiency and its role in neurological conditions: A review. Rev Neurol (Paris). 2016 Feb;172(2):109-22.

22. Bouillon R. Vitamin D and extraskeletal health. http://www.uptodate.com/contents/ vitamin-d-and-extraskeletal-health;

23. Theodoratou E., Tzoulaki I., Zgaga L., Ioannidis J.P. Vitamin D and multiple health 
outcomes: umbrella review of systematic reviews and meta-analyses of observational studies and randomised trials. BMJ 2014; 348:g2035.;

24. Chen S., Law C.S., Grigsby C.L., Olsen K., Hong T.T., Zhang Y., Yeghiazarians Y., Gardner D.G. Cardiomyocyte-specific deletion of the vitamin $D$ receptor gene results in cardiac hypertrophy. Circulation 2011, 124:1838-1847;

25. Wacker M., Holick F.M. Vitamin D-effects on skeletal and extraskeletal health and the need for supplementation. Nutrients 2013 Jan; 5(1): 111-148.

26. Visweswaran R.K., Lekha H. et al. Extraskeletal effects and manifestations of vitamin D deficiency. Indian J Endocrinol Metab. 2013 Jul-Aug; 17(4): 602-610.

27. Cedric F., Garland, Gorham E.D., Lipkin M. et al. The role of Vitamin D in Cencer
Prevention; Am J Public Health. 2006 February; 96(2): 252-261.

28. Köstner K., Denzer N., Müller C.S., Klein R., Tilgen W., Reichrath J. The relevance of vitamin $\mathrm{D}$ receptor (VDR) gene polymorphisms for cancer: a review of the literature. Anticancer Res. 2009 Sep;29(9):3511-36;

29. Penna-Martinez M., Ramos-Lopez E., Stern J., Hinsch N. et al. Vitamin d receptor polymorphisms in differentiated thyroid carcinoma. Thyroid, June 2009; 19(6):623-8;

30. Xavier, Rodrigues D.A. Vitamin D receptor (VDR) gene polymorphisms and genetic susceptibility to thyroid cancer. Oct 2013; http://hdl.handle.net/10400.6/1630;

31. Arik G., Ulger Z. Vitamin D in sarcopenia: Understanding its role in pathogenesis, prevention and treatment. European Geriatric Medicine 7(2016);207-213;

32. Ceglia L., Mayer J. Vitamin D and its role in skeletal muscle. Curr Opin Clin Nutr Metab Care, 2009 November; 12(6):628-633;

33. Rejnmark L. Effects of vitamin D on muscle function and performance: a review of evidence from randomized controlled trials. Ther Adv chronic Dis; 2(1); 2011;25-37;

34. Boland R.L. VDR activation of intracellular signaling pathways in skeletal muscle. $\mathrm{Mol}$ Cell Endocrinol 2011, 347:11-16;

35. Thomas M.K., Lloyd-Jones D.M., Thadhani R.I. et al. Hypovitaminosis D in medical inpatients. N Engl J Med 1998; 338:777.

36. Plotnikoff G.A., Quigley J.M. Prevalence of severe hypovitaminosis $D$ in patients with persistent, nonspecific musculoskeletal pain. Mayo Clin Proc 2003; 78:1463. 